\title{
Rebar Corrosion Monitoring and Prevention Techniques
}

\author{
Sooriyalakshmi. N, Jane Helena. H
}

\begin{abstract}
Corrosion is the gradual degradation of the metal by chemical reaction with the environment. The service life of the structure is a major concern that depends on the cost involved in construction, maintenance, and repair works. This paper discusses the corrosion mechanism, factors influencing corrosion, corrosion monitoring techniques, and corrosion protection methods. The monitoring techniques include the Linear polarization method, Active monitoring using sensors, DAQ cards, impedance measurement using chips, etc. Prevention methods include an application of paints with various chemical compositions, cathodic protection inhibitors, the use of fiberreinforced polymer, etc.
\end{abstract}

Keywords: Corrosion, Types of corrosion, Factors affecting corrosion, Active sensing, DAQ card, sensors, FRP, cathodic protection

\section{INTRODUCTION}

Corrosion of steel reduces the life and durability of the concrete [15]. Reinforced concrete structures undergo corrosion under different environmental conditions including carbonation, chloride attack, and in a marine environment. Corrosion products create volume change in the steel bar which in turn affects the surrounding concrete leading to cracks, delamination, spalling, etc. Galvanic corrosion, rebar corrosion, crevice, and pitting corrosion cause the degradation of performance and appearance of the concrete structures. To monitor the corrosion different techniques have been used worldwide. This paper discusses reinforcement corrosion, its mechanism, and monitoring methods, and its prevention

\section{CORROSION PROCESS}

The destruction or deterioration of the material and its properties by reaction with its environment is known as corrosion[3]. There is a difference in electrical potential due to which the concrete acts as an electrochemical cell [1]. It consists of an anode, cathode, and electrolyte solution which initiates the corrosion.

\section{MECHANISM OF CORROSION}

The formation of rust is influenced by the presence of oxygen, water, and iron. There are four criteria required to initiate corrosion,

Manuscript received on August 14, 2019

Revised Manuscript received on February 20, 2021.

Manuscript published on February 28, 2021

*corresponding author

N. Sooriyalakshmi*, Research scholar, Department of Civil Engineering, Anna University, Chennai, India, civil.sooriya@gmail.com

Dr. Jane Helena. H, Professor, Department of Civil Engineering, Anna University, Chennai, jane@annauniv.edu.

(C) The Authors. Published by Blue Eyes Intelligence Engineering and Sciences Publication (BEIESP). This is an open access article under the CC BY-NC-ND license (http://creativecommons.org/licenses/by-nc-nd/4.0/) viz rupture of passivating film depassivation, oxygen availability, and a conductive medium between anode and cathode.The Balanced chemical reaction of corrosion is

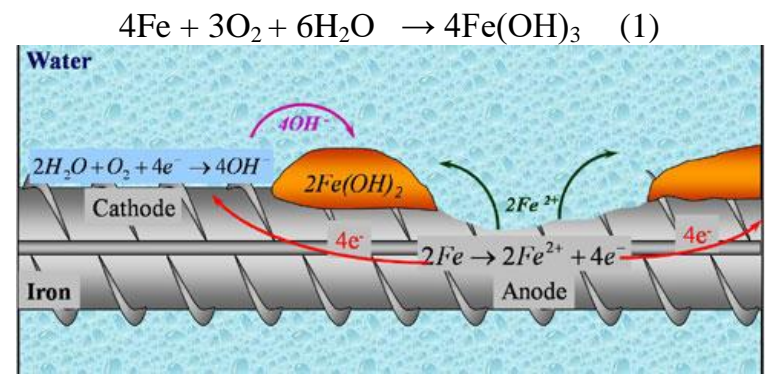

Fig.1 Corrosion process in concrete (Portland cement association, 2002)

Anodic reaction

$\mathrm{Fe} \rightarrow \mathrm{Fe}^{2+}+2 \mathrm{e}^{-}$

$\mathrm{Fe}^{2+}+2 \mathrm{OH}^{-} \rightarrow \mathrm{Fe}(\mathrm{OH})_{2}$

$4 \mathrm{Fe}^{2+}+4 \mathrm{H}^{+}+\mathrm{O}_{2} \rightarrow 4 \mathrm{Fe}^{3+}+2 \mathrm{H}_{2} \mathrm{O}$

$\mathrm{Fe}^{3+}+3 \mathrm{OH}^{-} \rightarrow \mathrm{Fe}(\mathrm{OH})_{3}$

Cathodic reaction

$4 \mathrm{e}^{-}+4 \mathrm{H}^{+}+\mathrm{O}_{2} \rightarrow 2 \mathrm{H}_{2} \mathrm{O}$

Ferric hydroxide is formed as a result of the above reactions. The solid iron dissolves into the electrolyte solution. The iron reacts with hydroxide ions in water to form ferrous hydroxide as green rust. This again reacts with hydroxide in water to form ferric hydroxide as the end product which is reddish rust.

\section{IV. \\ FACTORS AFFECTING CORROSION}

The various factors affecting corrosion are

- $\mathrm{pH}$

- Sodium Chloride

- Moisture

- Oxygen

- Environment

- Presence of chloride

- Carbonation

- Presence of acids like Conc. $\mathrm{H}_{2} \mathrm{SO}_{4}, \mathrm{HCl}, \mathrm{HF}, \mathrm{HNO}_{3}$, and $\mathrm{H}_{3} \mathrm{PO}_{4}$ (Phosphoric acid), etc. [12].

\section{CORROSION MONITORING TECHNIQUES}

\section{A. Linear polarization resistance method}

and Sciences Publication

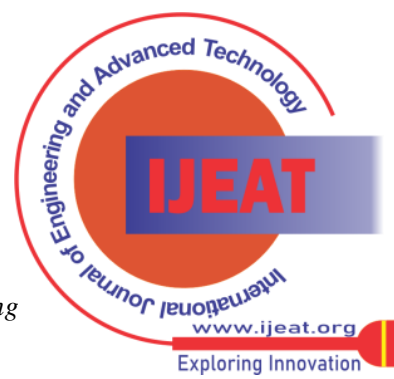


The linear polarization resistance method is a continuous electrochemical method for monitoring corrosion [7]. This technique helps to find the present condition of the reinforcement and to calculate the loss of rebar in crosssection within a few minutes [1]. The measuring instrument should possess the ability to maintain the electrode potential of 1 millivolt over a wide range of current and should have a high input impedance of $10 \mathrm{~m} \Omega$. The potential difference between the sensor electrodes is monitored and a suitable current is selected to maintain this potential difference throughout the LPR. This technique helps to identify the corrosion spot exactly.

\section{B. Impedance measuring chip}

The piezoceramic materials such as PZT (lead-zirconatetitanate) has been used in the field of sensing and actuation including the electromechanical impedance-based SHM techniques. The electromechanical impedance-based SHM technique utilizes piezoelectric patch sensors such as PZT and Macro Fiber Composites (MFC) sensors as self-sensing actuators. In this method, the analog components are used for the measurement of impedance [9].
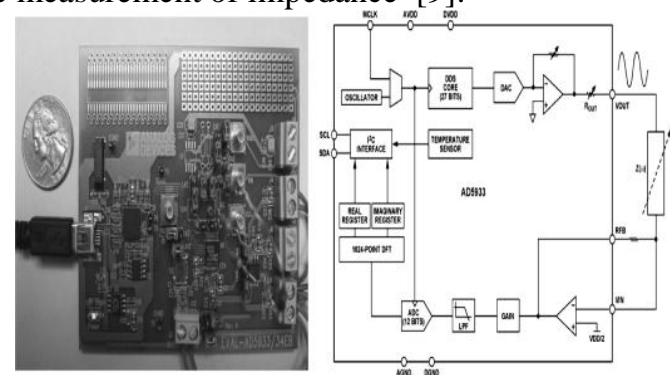

Fig.2 Miniature of impedance measuring chip and block diagram[11]

The active sensing devices used in the form of miniature impedance chip is shown in fig.2. The PZT sensor acts as the receiver on the structure. The corrosion is detected by the LED light if the light is red there is damage but if it glows green there is no damage. In this method, there is a great enhancement of safety and cost-saving.

\section{Monitoring using DAQ cards}

In this method, the data acquisition system is used to monitor corrosion through sensors embedded in samples. This acquisition system consists of signal conditioning, transducers, DAQ hardware, and software. Signals can be measured without any loss from the card up to a distance of about $10 \mathrm{~m}$. The potential at each point is measured by a high impedance voltmeter and is compared with the values from DAQ cards. This method has high accuracy [15].

\section{Gabor wavelet transform method}

A wavelet transform is the conversion of a one-dimensional signal into a three-dimensional signal. The first step involves denoising the received signal called wavelet thresholding. The threshold waveform of central frequency $50 \mathrm{KHz}$ is compared with the continuous wavelet transform. The contour is drawn with equal areas showing the presence of transverse cracks which can be considered as a global damage parameter. The frequency $(50 \mathrm{kHz}$ center frequency) causes waveform scattering, reflection, and mode conversion that can be captured through the Gabor wavelet transform [9].

\section{E.Electrochemical Impedance Spectroscopy(EIS)}

Electrochemical impedance spectroscopy helps to know the corrosion rate directly from the polarization potential. When a small AC potential is applied to the specimen with different frequencies, it records the response and analyzes the clusters of frequency in a domain. The EIS method measures both the resistance and capacitance of the system

\section{F. Sputtering Deposition Techniques}

Sputtering is the process of bombarding the target with energetic ions to form vapor particles. Optical fiber is placed in a vacuum compartment with the split ends facing an iron target. An experiment is performed using a glass plate with a strip of thin tape bonded to the surface. The plate is kept at a distance to the surface hit by electrons that is equal to the fiber/target distance in the actual sputtering process. The sputtering deposition is conducted for various periods [6].

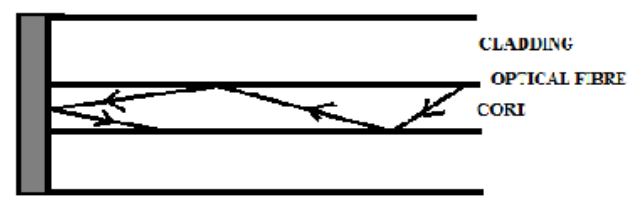

Fig.3 Sputtering deposition Techniques

After the deposition process is completed, the tape is stripped off and the thickness of the coated film is shown in fig.3 is obtained from the surface profile along with the coated plate, measured with a profilometer. The reflected signal from the fiber end is monitored using Optical Time Domain Reflectometer (OTDR).

\section{G. Electromechanical Admittance (EMA)}

The EMA technique uses piezoelectric materials to generate a surface electric charge. When mechanical stress is applied it undergoes mechanical deformation in response to an applied electric field [11]. In this method, the electromechanical impedance of the structure before damage is taken as reference. When the sensor is actuated there will be a change in impedance by the exciting signal which demonstrates the damage to the structure. The excitation frequency is an important parameter that must be taken into account. Variation in admittance signature indicates the damage of the structure [5].

\section{G. Monitoring using a potentiostat}

In this method, a constant potential is applied and the corresponding polarization current is taken as output. This method is useful for detecting chloride penetrating pitting corrosion. When the chloride content increases and depassivation of steel take place it indicates the onset of corrosion. 
The polarization potentiometric test is used to determine the initiation of corrosion by placing the reference electrode close to the reinforcement [4].

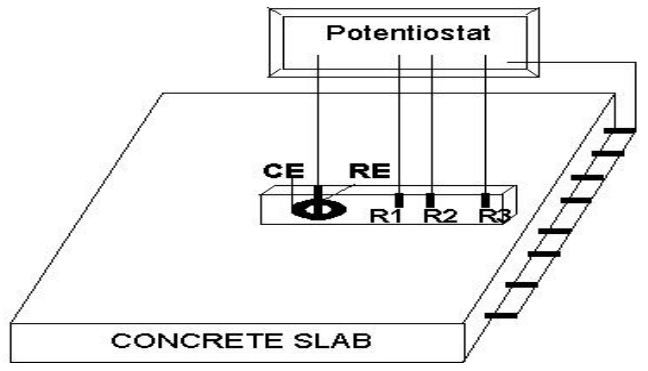

Fig.4 Setup to monitor using potentiostat [1]

In figure $4 \mathrm{RE}$ refers to the Reference electrode and $\mathrm{CE}$ refers to the Counter electrode. R1, R2, R3 are the reinforcement.

\section{H. Infrared thermal imaging techniques}

IR radiation is an electromagnetic wave with wavelength ranges from 0.75 to $1000 \mu \mathrm{m}$ [8]. The temperature on the surface is measured by infrared radiation given by the external source. Different spatial distribution is obtained from the different wavelengths of infrared rays. The difference in temperature states the level of damage to concrete structures.

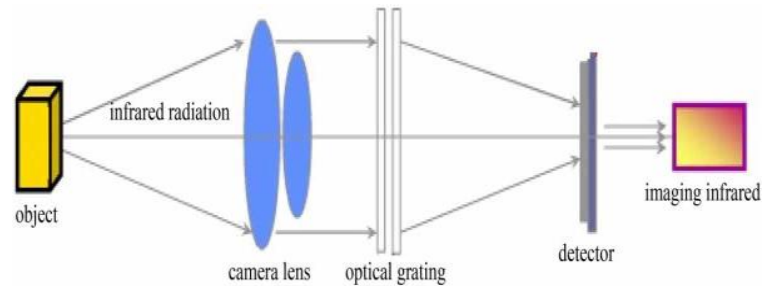

Fig.5 Imaging infrared system[8]

The color of the images varies from green to light red until it becomes white.

\section{I.Impressed current method}

In the impressed current method, the anode is connected to the rebar and the negative terminal cathode is connected to the steel mesh. When DC is applied corrosion is initiated and Faraday's law is used to measure the time of reaction and the rate of corrosion [14].

\section{J. Acoustic emission method}

The principle in this method is the conversion of physical displacement into voltage[7]. When the waves propagate inside the concrete there is expansion and increase in volume. Ultrasonic waves propagate through the material and help to find the internal flaws[7]. Wave propagation may vary with different metallic layers by acoustic emission.

\section{K. Electrical resistance method}

The electrical resistance method is one of the online monitoring techniques which can measure the electrochemical and mechanical parameters of corrosion. Merits of the electrical resistance technique is that corrosion monitoring can be made without seeing or removing the sample. The response is quick and can be monitored continuously. A sudden increase in corrosion rate can be detected and immediate remedial action can be implemented [7].

\section{CORROSION PREVENTION TECHNIQUES}

\section{A. Cathodic and anodic protection}

Cathodic protection is the movement of electrons from electrolyte towards the metal to be protected on the application of current. The cathodic protection can be achieved in two ways viz by an external power supply and by galvanic coupling[10]. The current applied to the anode increases the dissolution rate of the metal and decreases the rate of corrosion[2].

\section{B. Inhibitors}

A substance, when added in a small proportion, can reduce the corrosion rate. Organic compounds like Chromate, nitrate, and ferric salt can adsorb on the metal surface and suppress the metal dissolution [12]. Sodium hydroxide suppresses the cathodic reaction thereby reducing the corrosion potential of the steel [2].

\section{Steel coating and painting}

The coating gives resistance against ion current. The metal to be coated is immersed in an electrolyte solution called electroplating. The coating can also be done by dipping the metal in a hot molten bath with less melting point. Galvanized steel is an example of hot dipping. The most common chemical conversion treatments on the cleaned metal surface are coating a layer of phosphate, coating with a layer of metal chromate, chromium-free pretreatments, anodizing of aluminium, engraving, and painting with an etching primer. They improve the adhesion of the paint material to the metal surface and decelerate corrosion underneath the coating. Coatings for rebar protection in concrete can be metallic, organic, and cementitious [2]. The most common types of paints for corrosive environments are Acrylic, Alkyd, Epoxy Chlorinated rubber $\left(\mathrm{C}_{10} \mathrm{H}_{11} \mathrm{Cl}_{7}\right)$, Polyurethane $\quad\left(\mathrm{C}_{27} \mathrm{H}_{36} \mathrm{~N}_{2} \mathrm{O}_{10}\right)$, aliphatic Polyurethane combinations, purified urethane tar Ethyl zinc silicate, Epoxy zinc, $\mathrm{C}_{2} \mathrm{H}_{3} \mathrm{Cl}[10]$.

\section{Fiber-reinforced polymer}

There are four types of FRP viz aramid fiber, Glass fiber, Carbon fiber, and Basalt fiber. Carbon and basalt fiber are resistant to an acidic and alkaline environment. $70 \%$ of corrosion expansion is reduced by CFRP laminates. Corrosion can be reduced and the liberation of corrosion products can be prevented [13]. Woven fiberglass can also be used as reinforcement because fiberglass is non conductive [9].

\section{CONCLUSION}

It is concluded that reinforcement corrosion is a major issue affecting the durability of the structure. When structures are to be constructed in an aggressive environment special care should be taken before construction. Studying the corrosion mechanism helps for suitable protection methods. Different monitoring techniques are cost-effective and give accurate results. The various parameters viz the amount of chloride penetration, corrosion rate, polarization resistance can be determined by using sensors and methods.

Blue Eyes Intelligence Engineering DOI:10.35940/ijeat.F8782.0210321

Journal Website: www.ijeat.org

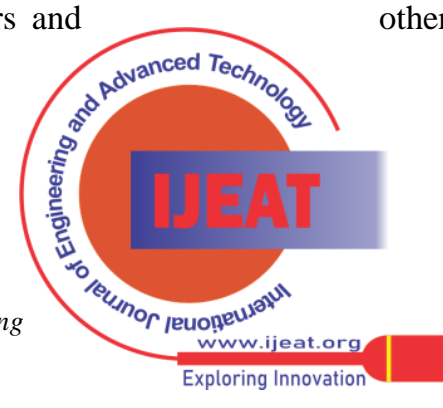




\section{Rebar Corrosion Monitoring and Prevention Techniques}

More than one protection method can also be used to prevent corrosion or reduce further development of cracks.

\section{REFERENCES}

1. Andrade. C and C. Alonso with contribution from J.Gulikers, R.Polder, R.Cigna, O.Vennesland, M.Salta, A.Raharinaivo and B.Elsener(2004), "Test methods for on-site corrosion rate measurement of steel reinforcement in concrete by means of the polarization resistance method", Journal of Material and Structures, Vol.37, pp:623-643.

2. Arpit Goyal, Homayoon Sadeghi Pouya, Eshmaiel Ganjian, Peter Claisse (2018), “ A review of corrosion and protection of steel in concrete", Arabian journal of science and engineering, doi.org/10.1007/s13369-018-3303-2.

3. ASTM G193 Standard Terminology and Acronyms Relating to corrosion, ASTM international, www.astm.org

4. L. Bertolini and E. Redaelli (2009), "Depassivation of steel reinforcement in case of pitting corrosion: detection techniques for laboratory studies", Journals of materials and corrosion, Vol.60(8), pp:608-616. DOI: 10.1002/maco.200905276.

5. Chris G.Karayannis, Constantin E. Chalioris, Georgia M.Angeli, Nikos A.Papadopoulos, Maria J.Favvata, Costas P. Providakis(2016) "Experimental damage evaluation of reinforced concrete steel bars using piezoelectric sensors", Journal on construction and Building materials, Vol.105, pp:227-244.

6. Christopher K.Y.Leung, Kai Tai Wan and Liquan Che(2008), "A Novel Optical fibre sensor for steel corrosion in concrete structures", Sensors, Vol.8, pp:1960-1976.

7. Devesh P. Kansara, Akshay P. Sorathiya and Himanshukumar R. Patel (2018), “ Corrosion Monitoring and Detection Techniques in Petrochemical Refineries", IOSR Journal of Electrical and Electronics Engineering (IOSR-JEEE), Vol.13(2), pp:85-93.

8. H.X. Du, H.P. Wu, F.J. Wang, and R.Z. Yan (2015), "The detection of high strength concrete exposed to high temperatures using infrared thermal imaging technique", Journal of materials research Innovations, Vol.19, pp:162-167.

9. Hong-YueTang, Charles Winkelmann, Wahyu Lestari, and Valeria La Saponara(2011), "Composite Structural Health Monitoring Through Use of Embedded PZT Sensors", Journal of Intelligent Material Systems and Structures, Vol.22(8), DOI:10.1177/1045389X11406303.

10. ISO 12944-5 Paints and varnishes-Corrosion protection of steel structures by protective paint systems - part 5: Protective paint system.

11. Kevin K Tseng and Liang sheng Wang (2004), "Smart piezoelectric transducers for in situ health monitoring of concrete", Journal of smart materials and structures", Vol. 13, pp:1017-1024.

12. Mars.G.Fontana, "Corrosion Engineering(2005)",

13. Moataz Badawi and Khaled Soudki (2004), "Control of CorrosionInduced Damage in Reinforced Concrete Beams Using Carbon FiberReinforced Polymer Laminates, Journal of composites for construction, Vol.9, pp:195-201.

14. Prasad V. Bahekar, Dr. Sangeeta S. Gadve(2019)," Effects of Impressed Current Cathodic Protection on carbon FRP Strengthened Flexural Reinforced Concrete Members", Corrosion Science, Vol.75(6), pp: 693-703, doi.org/10.5006/2916.

15. Thirumalai Parthiban, R. Ravi. G.T. Parthiban (2006), "Potential monitoring system for corrosion of steel in concrete", Journal for Advances in Engineering Software, Vol.37, pp:375-381.

\section{AUTHORS PROFILE}

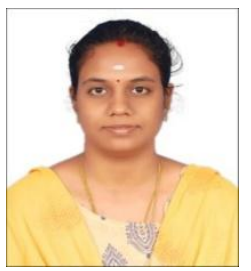

N. Sooriyalakshmi, presently a Research scholar in the Division of Structural Engineering, College of Engineering, Guindy, Anna University, Chennai- 600025. Her area of interest is Corrosion Engineering, Sandwich Wall Panels and, Thermal Performance Studies. She is a life member of the Indian Society for Technical Education, Member of the Indian Concrete Institute student chapter.

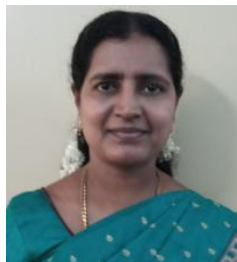

Dr. H. Jane Helena, Professor in the Division of Structural Engineering, Department of Civil Engineering, College of Engineering, Guindy, Anna University, Chennai-600025. She is having 20years of teaching experience. Her areas of interest are Steel Structures, Steel-Concrete composites and Computer-Aided Design. She has

Published By:

Blue Eyes Intelligence Engineering

published nearly 45 papers in International and National conferences and her paper titled "Finite element Study on Corrugated Web Steel Girders with Cutouts" received the best paper award given by Incheon Nationa University, Incheon from South Korea in 2018. She has organized several Structure and Steel-Concrete Composite Structures. She has published 3 books namely Design of Steel structures, Structural Engineering Design and Drawing, and Theory of Elasticity and Plasticity. She has guided 2 Doctoral scholars. Eight scholars are pursuing their research under her (che has guided 44 postgraduate students' dissertation works. She completed many funded projects sponsored by different funding agencies. She has published nearly 20 papers in various National and International Journals. She is a member of various professional bodies such as Life Member of INSDAG, Member of Indian Concrete Institute,

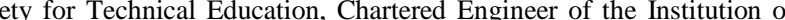
Engineers, Member of Indian Association of Earthquake Technology 